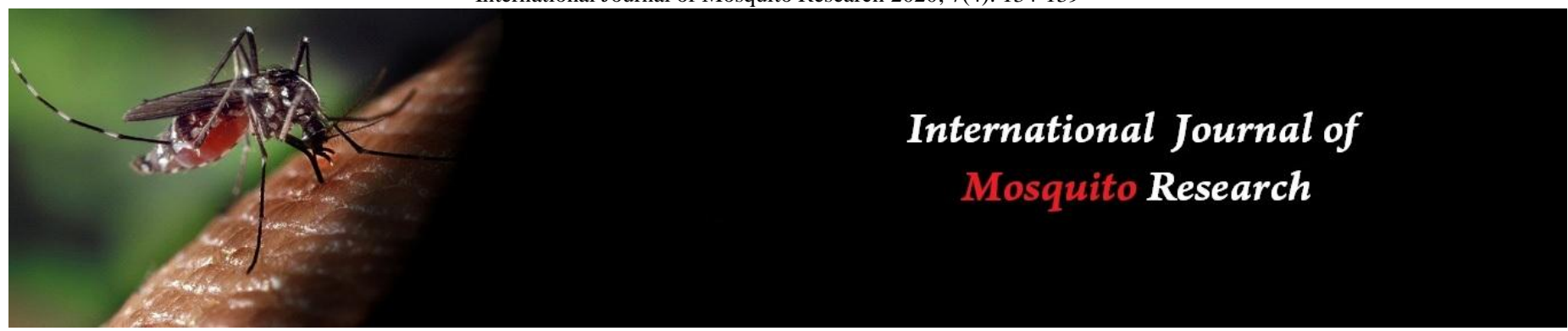

ISSN: 2348-5906

CODEN: IJMRK2

IJMR 2020; 7(4): 134-139

(C) 2020 IJMR

Received: 09-05-2020

Accepted: 02-07-2020

Indranil Bhattacharjee

P.G. Department of Zoology,

Raja Narendra Lal Khan

Women's College, Autonomous,

Natural and Applied Science

Research Centre, Paschim

Medinipur, West Bengal, India

Department of Zoology, Dr. Bhupendranath Dutta Smriti

Mahavidyalaya, Hatgobindapur,

West Bengal, India

Biplab Mandal

Department of Zoology,

Vidyasagar University, Paschim

Medinipur, West Bengal, India

Partha Pratim Chakravorty P.G. Department of Zoology, Raja Narendra Lal Khan

Women's College, Autonomous,

Natural and Applied Science

Research Centre, Paschim

Medinipur, West Bengal, India
Corresponding Author: Partha Pratim Chakravorty P.G. Department of Zoology, Raja Narendra Lal Khan

Women's College, Autonomous, Natural and Applied Science Research Centre, Paschim Medinipur, West Bengal, India

\section{Influence of nature in controlling filarial transmission: A study in slums of Burdwan}

\author{
Indranil Bhattacharjee, Biplab Mandal and Partha Pratim Chakravorty
}

DOI: https://doi.org/10.22271/23487941.2020.v7.i4b.470

\section{Abstract}

Purpose: Lymphatic filariasis is a crippling disease which affects the health status as well as economic condition of a person and also the society. Many attempts are made by scientists all over the world to control the filarial worm as well as vector. But nature plays important role in controlling the filariasis.

Methods: To have some clear picture on how nature helps to control transmission of filarial disease, four slums of Burdwan (Hatgobindapur, Pandaveswar, Jamuria and Memari) were sampled for Daily survival rate (DSR), Daily Mortality Rate (DMR), Presumptive Mortality Rate (PMR) and Ovariolar dilatatations. Results: Lack of synchronization between the highest vector density and transmission disease, fall in parasitic load, mortality between two successive gonotrophic cycles, rise and fall in temperature and humidity is noticed in all the four slums which help to keep the check on transmission level of filaria by nature itself.

Conclusions: Factors behind the natural phenomena of control is reflected in this article which perhaps helps to adopt strategies for effective control.

Keywords: Filaria, control, burdwan, slums, nature

\section{Introduction}

The lymphatic filariasis is a public health problem, and it is of great concern today. It is a painful, disfiguring disease. It is debilitating diseases and affects the socioeconomic status of human as most of the affected persons are morbid. The main parasites are Wuchereria bancrofti, Brugia malayi and Brugia timori. The main vectors are the species of the genera Culex, and Mansonia. At least 1307 million people in 83 countries including 553.7 million people in India are at risk [1-2]

Information regarding the epidemiology of filaria is recorded from different parts of West Bengal by different scientists from time to time ${ }^{[3-13]}$.

Effects related with environmental change profound in modulating natural ecosystems. Climate change coupled with rapid urbanization is stimulating unprecedented change in population dynamics and status of mosquito borne diseases ${ }^{[14]}$. Scientists over different parts of the world trying their best to control the filarial parasites by applying different modes of control mainly by reducing both the vector and parasite populations through different means. But still the outcome of the program is not so much satisfactory. But nature itself plays important role in controlling the parasites ${ }^{[15-16]}$. So, we can avail ourselves of natural control of filariasis simply by controlling indiscriminate urbanization, controlling deforestation, proper sanitization and reducing the source of vector mosquito to breed. Ecological transformations, rapid and uncoordinated urbanizations of rural area mainly due to the construction of dams, irrigation canals, poor design and lack of maintenance of sewage water, water storage tanks and urban subsistence agriculture can facilitate increase of vector population transmitting filaria and other vector borne diseases ${ }^{[17-18]}$. In the year 1975 the proportion of urban dwellers in the least developed countries was only $27 \%$ which rose to $40 \%$ by the year 2000 . Fifty percent of the world's urban population is concentrated in Asia. Currently, the annual growth rate in Asian cities is $2.7 \%{ }^{[19]}$. This implies that in the future, an increasing number of habitats with organically polluted water will be available for Culex vectors ${ }^{[20]}$.

This paper highlights on how nature plays important role in controlling the filarial outbreak in slums (Hatgobindapur, Pandaveswar, Jamuria and Memari) of Burdwan District, West Bengal, India. 


\section{Materials and Methods}

Indoor resting mosquitoes were collected in the morning, once in a month from 10 fixed human habitations (shelters) of four slums (Hatgobindapur $\left(23.25^{\circ} \mathrm{C} \mathrm{N}, 87.97^{\circ} \mathrm{C} \mathrm{E}\right.$ ), Pandaveswar $\left(23.70^{\circ} \mathrm{C} \mathrm{N}, 87.27^{\circ} \mathrm{C} \mathrm{E}\right)$, Jamuria $\left(23.70^{\circ} \mathrm{C} \mathrm{N}, 87.07^{\circ} \mathrm{C} \mathrm{E}\right)$ and Memari $\left(23.17^{\circ} \mathrm{C} \mathrm{N}, 88.10^{\circ} \mathrm{C} \mathrm{E}\right)$ of Burdwan, West Bengal, India from March 2018 to February 2020. Collections were made in all the seasons of the year namely summer (MarchJune), Rainy (July-October), winter (November-February) following the method of De and Chandra ${ }^{[21]}$. We have visited slums once in a month thus 12 times in a year having 10 shelters. Thus in two year we have visited 240 shelters in each slum. Thus in two year we have visited 960 shelters in four slums. We have also collected data from meterological department regarding maximum and minimum temperature and rainfall. Collected mosquitoes were identified and Culex quinquefasciatus were dissected for the search of developing filarial larvae including microfilariae $(m f)$. Ovariolar dilatations of mosquitoes were examined by the method of Polovodova ${ }^{[22]}$ which were collected in the morning hours from all the four slums in all the three seasons. DSR and DMR were calculated with the method of Davidson ${ }^{[23]}$ and Service [24] and PMR between two successive age groups were calculated by the help of method of Gillies and Wilkes ${ }^{[25]}$. Statistical analysis was done using Students t-test [26]. Standardized effect size is calculated by using Cohen's $d$ which is calculated by dividing the mean difference by the observed standard deviation. Assumption check under normality is also done using free software JASP $(0.12 .2)$ which mainly tests the null hypothesis that the dependent variable is normally distributed.

\section{Results}

Rainy season was found to be the high time for transmission of filarial disease in slums of Burdwan which is established by its highest infection and infectivity rates of the vector in nature and also the developmental period is short (Table 1). When seasonal variations of vector population were assessed, density was found to be significantly lower $(P>0.05)$ in the rainy season in comparisons to other seasons in all the slums.

Number of $C x$. quinquefascitus infected with $m f$, first, second, and third stage larvae of $W$. bancrofti gradually declines in all the slums (Table 2). It indicates that all the $m f$ that enter into the GI tract of mosquito cannot develop into L3 stage.
A high percentage of mortality of vector population collected from all the four slums of Burdwan was observed between two successive gonotrophic cycles (Table 3). Most of the mosquitoes carrying $m f$ were found to be nulliparous (yet to lay first batches of eggs) i.e. took $m f$ during their first blood meal. Results of statistical analysis regarding one sample student $t$ test, descriptive and assumption checks of Vector Prevalence, Vector infection rate, Vector Infectivity Rate and Parasitic Load is presented in Table 4 . The computed $t_{0.05(3)}$ for vector prevalence for different seasons (summer, rainy, and winter) are 10.698, 4.387 and 11.075; for vector infection rate the values are 2.970, 2.630 and 3.493; for vector infectivity rate the values are $3.555,3.638$ and 1.732 ; and for parasitic load the $t$ value for $m f$ is 9.966 , for $1^{\text {st }}$ stage, it is 6.328 , for $2^{\text {nd }}$ stage it is 5.551 and for $3^{\text {rd }}$ stage the value is 2.774 respectively and all the values are far high from tabulated $t_{0.05(3)}$ value 2.353 . So, the probability $\mathrm{P}$ of the $\mathrm{H}_{0}$ being correct is lower than 0.05 $(P<0.05)$. It is considered too low. So the $\mathrm{H}_{0}$ is rejected and it is inferred there is significant difference.

Cohen's d provides standardized method for comparing results. It describes the mean of the two groups normalized to pool SD of the two groups. The Cohen's d value of vector prevalence for different seasons (summer, rainy, and winter) are 5.349, 2.194 and 5.537; for vector infection rate the values are 1.485, 1.315 and 1.747 ; for vector infectivity rate the values are 1.778 , 1.819 and 0.866 ; and for parasitic load of $m f$ the value is 4.983, for $1^{\text {st }}$ stage, it is 3.164 , for $2^{\text {nd }}$ stage it is 2.775 and for $3^{\text {rd }}$ stage the value is 1.387 respectively.

The Shapiro-Wilk test values for vector prevalence for different seasons (summer, rainy and winter) are 0.822, 0.928 and 0.775 respectively, for vector infection rate the values are $0.862,0.843$ and 0.969 respectively; for vector infectivity rate the values are $0.862,0.821$ and 0.729 respectively and the values for parasitic load of $\mathrm{mf}$ is $0.986,1^{\text {st }}$ stage $0.915,2^{\text {nd }}$ stage 0.928 and for $3^{\text {rd }}$ stage 0.908 respectively and the values was not significant for vector prevalence, vector infection rate and vector infectivity rate in different seasons, and the data were normally distributed $(P>0.05)$ and in similar manner the values for $\mathrm{mf}, 1^{\text {st }}$ stage, $2^{\text {nd }}$ stage and $3^{\text {rd }}$ stage the values were not significant, and the data was normally distributed $(P>0.05)$. Maximum and minimum temperature, rainfall, humidity and, number of $C x$. quinquefasciatus average of two year (March 2018 to February 2020) is plotted in Figure 1.

Table 1: Season wise vector prevalence, infection rate, infectivity rate and duration of parasitic development in vector $C x$. quinquefasciatus in slums of Burdwan

\begin{tabular}{|c|c|c|c|c|}
\hline Seasons & Slums & Summer & Rainy & Winter \\
\hline \multirow{4}{*}{ Vector prevalence (Cx. quinquefasciatus) \% } & Hatgobindapur & 28.75 & 26.82 & 31.45 \\
\cline { 2 - 5 } & Pandaveswar & 41.30 & 32.07 & 43.44 \\
\cline { 2 - 5 } & Jamuria & 40.09 & 38.04 & 42.41 \\
\cline { 2 - 5 } & Memari & 30.08 & 9.78 & 31.22 \\
\hline \multirow{4}{*}{ Vector infection Rate (Cx. quinquefasciatus) \% } & Hatgobindapur & 1.25 & 3.99 & 0.68 \\
\cline { 2 - 5 } & Pandaveswar & 1.82 & 7.77 & 0.87 \\
\cline { 2 - 5 } & Jamuria & 0.45 & 1.68 & 0.38 \\
\cline { 2 - 5 } & Memari & 0.45 & 1.68 & 0.19 \\
\hline \multirow{4}{*}{ Vector infectivity Rate (Cx. quinquefasciatus) \% $\%$} & Hatgobindapur & 0.22 & 1.05 & 0.19 \\
\cline { 2 - 5 } & Pandaveswar & 0.34 & 1.26 & 0.19 \\
\cline { 2 - 5 } & Jamuria & 0.11 & 0.42 & 0 \\
\cline { 2 - 5 } & Memari & 0.11 & 0.42 & 0 \\
\hline Developmental period (Days) & All slum average & 3.96 & 3.71 & 5.83 \\
\hline
\end{tabular}


Table 2: Gradual fall in Parasitic Load

\begin{tabular}{|c|c|c|c|c|}
\hline Area & & \multicolumn{3}{|c|}{ Average load per infected mosquito vector $\boldsymbol{m} \boldsymbol{f}$} \\
\hline Slums of Burdwan & $\boldsymbol{m} \boldsymbol{f}$ & $\mathbf{1}^{\text {st }}$ Stage & $\mathbf{2}^{\text {nd }}$ Stage & $\mathbf{3}^{\text {rd }}$ Stage \\
\hline Hatgobindapur & 4.80 & 3.00 & 2.00 & 1.04 \\
\hline Pandaveswar & 4.00 & 3.50 & 3.00 & 1.54 \\
\hline Jamuria & 3.50 & 2.78 & 1.67 & 1.00 \\
\hline Memari & 3.00 & 1.50 & 1.33 & 0.00 \\
\hline
\end{tabular}

Table 3: Average presumptive mortality rate of Cx. quinquefasciatus, population between two successive gonotrophic cycles

\begin{tabular}{|l|c|c|ccc|c|}
\hline Area & \multicolumn{7}{|c|}{ Parity } \\
\hline Slums of Burdwan & NP & P1 & P2 & P3 & P4 & P5 \\
\hline Hatgobindapur & 51.35 & 44.44 & 40.00 & 33.33 & 25.00 \\
\hline Pandaveswar & 50.00 & 40.00 & 37.50 & 33.33 & 30.00 \\
\hline Jamuria & 55.56 & 50.00 & 45.00 & 36.36 & 28.57 \\
\hline Memari & 4.0 & 50.00 & 40.00 & 33.33 & 25.00 \\
\hline
\end{tabular}

Table 4: One sample student t test, descriptives and assumption checks of Vector Prevalence, Vector infection rate, Vector Infectivity Rate and Parasitic Load

a. Vector Prevalence

One Sample t test

\begin{tabular}{|c|c|c|c|c|}
\hline Season & $\mathbf{t}$ & $\mathbf{d f}$ & $\mathbf{p}$ & Cohen's d \\
\hline Summer & 10.698 & 3 & 0.002 & 5.349 \\
\hline Rainy & 4.387 & 3 & 0.022 & 2.194 \\
\hline Winter & 11.075 & 3 & 0.002 & 5.537 \\
\hline
\end{tabular}

\section{Descriptives}

\begin{tabular}{|c|c|c|c|c|}
\hline Season & N & Mean & SD & SE \\
\hline Summer & 4 & 35.055 & 6.554 & 3.277 \\
\hline Rainy & 4 & 26.677 & 12.162 & 6.081 \\
\hline Winter & 4 & 37.130 & 6.705 & 3.353 \\
\hline
\end{tabular}

\section{Assumption Checks}

Test of Normality (Shapiro- Wilk)

\begin{tabular}{|c|c|c|}
\hline Season & W & p \\
\hline Summer & 0.822 & 0.147 \\
\hline Rainy & 0.928 & 0.584 \\
\hline Winter & 0.775 & 0.064 \\
\hline
\end{tabular}

\section{b. Vector Infection Rate \\ One Sample t test}

\begin{tabular}{|c|c|c|c|c|}
\hline Season & t & df & p & Cohen's d \\
\hline Summer & 2.970 & 3 & 0.059 & 1.485 \\
\hline Rainy & 2.630 & 3 & 0.078 & 1.315 \\
\hline Winter & 3.493 & 3 & 0.040 & 1.747 \\
\hline
\end{tabular}

\section{Descriptives}

\begin{tabular}{|c|c|c|c|c|}
\hline Season & $\mathbf{N}$ & Mean & SD & SE \\
\hline Summer & 4 & 0.993 & 0.668 & 0.334 \\
\hline Rainy & 4 & 3.780 & 2.874 & 1.437 \\
\hline Winter & 4 & 0.530 & 0.303 & 0.152 \\
\hline
\end{tabular}

Assumption Checks

Test of Normality (Shapiro- Wilk)

\begin{tabular}{|c|c|c|}
\hline Season & W & p \\
\hline Summer & 0.862 & 0.267 \\
\hline Rainy & 0.843 & 0.203 \\
\hline Winter & 0.969 & 0.833 \\
\hline
\end{tabular}

\section{c. Vector Infectivity Rate}

\section{One Sample t test}

\begin{tabular}{|c|c|c|c|c|}
\hline Season & t & df & p & Cohen's d \\
\hline Summer & 3.555 & 3 & 0.038 & 1.778 \\
\hline Rainy & 3.638 & 3 & 0.036 & 1.819 \\
\hline Winter & 1.732 & 3 & 0.182 & 0.866 \\
\hline
\end{tabular}

\section{Descriptives}

\begin{tabular}{|c|c|c|c|c|}
\hline Season & N & Mean & SD & SE \\
\hline Summer & 4 & 0.195 & 0.110 & 0.055 \\
\hline Rainy & 4 & 0.787 & 0.433 & 0.216 \\
\hline Winter & 4 & 0.095 & 0.110 & 0.055 \\
\hline
\end{tabular}

Assumption Checks

Test of Normality (Shapiro- Wilk)

\begin{tabular}{|c|c|c|}
\hline Season & W & p \\
\hline Summer & 0.862 & 0.266 \\
\hline Rainy & 0.827 & 0.161 \\
\hline Winter & 0.729 & 0.024 \\
\hline
\end{tabular}

\section{d. Parasitic Load}

One Sample t test

\begin{tabular}{|c|c|c|c|c|}
\hline Season & $\mathbf{t}$ & $\mathbf{d f}$ & $\mathbf{p}$ & Cohen's d \\
\hline $\mathrm{mf}$ & 9.966 & 3 & 0.002 & 4.983 \\
\hline $1^{\text {st }}$ stage & 6.328 & 3 & 0.008 & 3.164 \\
\hline $2^{\text {nd }}$ Stage & 5.551 & 3 & 0.012 & 2.775 \\
\hline $3^{\text {rd }}$ Stage & 2.774 & 3 & 0.069 & 1.387 \\
\hline
\end{tabular}

\section{Descriptives}

\begin{tabular}{|c|c|c|c|c|}
\hline Season & $\mathbf{N}$ & Mean & SD & SE \\
\hline $\mathrm{mf}$ & 4 & 3.825 & 0.768 & 0.384 \\
\hline $1^{\text {st }}$ stage & 4 & 2.695 & 0.852 & 0.426 \\
\hline $2^{\text {nd }}$ Stage & 4 & 2.000 & 0.721 & 0.360 \\
\hline $3^{\text {rd }}$ Stage & 4 & 0.895 & 0.645 & 0.323 \\
\hline
\end{tabular}

\section{Assumption Checks}

Test of Normality (Shapiro- Wilk)

\begin{tabular}{|c|c|c|}
\hline Season & W & p \\
\hline $\mathrm{mf}$ & 0.986 & 0.937 \\
\hline $1^{\text {st }}$ stage & 0.915 & 0.509 \\
\hline $2^{\text {nd }}$ Stage & 0.928 & 0.585 \\
\hline $3^{\text {rd }}$ Stage & 0.908 & 0.472 \\
\hline
\end{tabular}




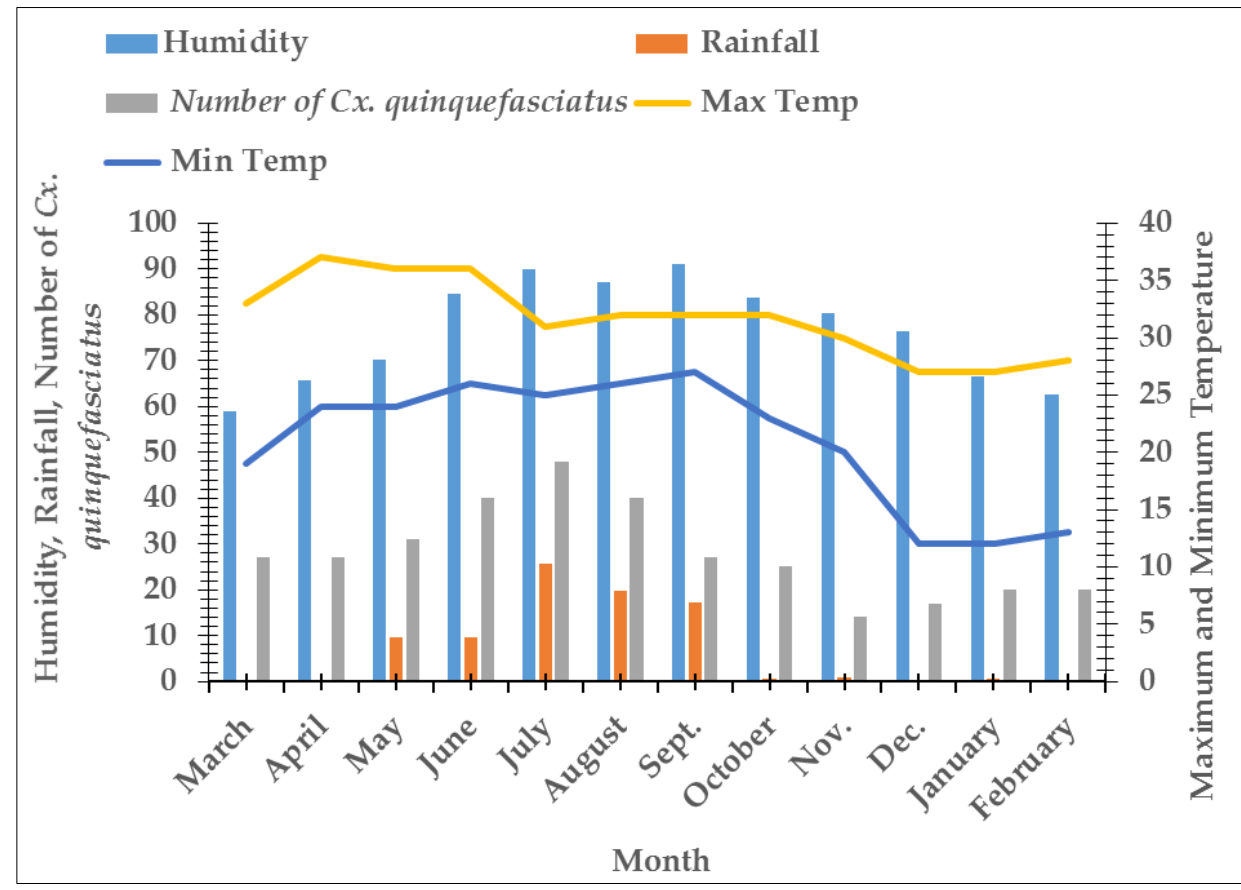

Fig 1: Maximum and minimum temperature, rainfall, humidity and number of Cx. quinquefasciatus average of two year (March 2018 to February 2020)

\section{Discussions}

Density of vector is found to be significantly lower in rainy season perhaps their breeding places might flooded during rainy season in comparison to other seasons ${ }^{16}$ than other and developmental period is also shorter than other season but infection and infectivity rate is high in rainy season which indicates that there is lack of synchronization between highest vector density and transmission disease which helps to keep check on transmission level of filaria by nature itself.

Fall in parasitic load indicates that $\mathrm{mf}$ are damaged by the buccopharyngeal armature of the vector mosquito during the process of ingestion [27]. Sometimes it is also noticed that migrating $m f$ are rapidly excreted by vector mosquitoes, thus limiting them ${ }^{[28-29]}$.

A high mortality between two successive gonotrophic cycles caused reduction of vector as well as parasite population naturally ${ }^{[3-11]}$.

Rise and fall in temperature and humidity leads to deformity and degeneration of large number of parasites in the body of the mosquito ${ }^{[30]}$ itself and thus it limits the transmission of filarial disease. Moreover in the natural conditions where the mosquito lay eggs there are number of predatory fishes which feeds on mosquito immature and destroy them [31-57]. Besides fish arthropod larvae ${ }^{[58-63]}$ also plays role in controlling mosquito population under control. We can easily control vector population simply by undisturbing environment. Rapid urbanization, deforestation disturbs nature. We can easily help us by helping nature in retaining its own features avoiding manipulations of nature.

\section{Conflict of Interest}

We declare that we have no conflict of interest.

\section{Ethical approval}

This article is not under consideration or published elsewhere. Ethical clearance for the study was obtained from IAEC, Approval No. 23/IAEC (06)/RNLKWC/2020, Dated 08.02.2020.

\section{Acknowledgment}

Authors are grateful to Principal, PG Department of Zoology, Raja Narendra Lal Khan Women's College (Autonomous) Natural and Applied Science Research Centre, Paschim Medinipore, West Bengal, India for the facilities provided and acknowledge the support to IB to carry out the paper as a part of the thesis under Vidyasagar University, Raja Narendra Lal Khan Women's College (Autonomous).

Authors Contribution: IB: Data curation, Writing Original Draft, Statistical analysis BM: Reviewing, Editing PPC: Designing, Monitoring, Reviewing, Communication.

\section{References}

1. WHO. Global programme to eliminate lymphatic filariasis. World Health Organization. Weekly Epidemiol Rec. 2007; 82:361-380.

2. Chandra G, Paramanik M, Mondal SK, Ghosh AK. Comparative Studies of different indices related to filarial vector of a Rural and an urban area of West Bengal, India. Trop Med. Surg, 2013, 104. doi:10.4172/23299088.1000104.

3. Hati AK, Chandra G, Bhattacharyya A, Biswas D, Chatterjee KK, Dwibedi HN. Annual transmission potential of bancroftian filariasis in an urban and a rural area of West Bengal, India. Am J Trop Med Hyg. 1989; 40(4):305-307.

4. Adhikari P, Halder JP. Prevalence of bancroftian filariasis in Burdwan district, W. B. II. Vector and microfilariae density in Colliery and non Colliery areas. J Commun Dis. 1995; 27:181-185.

5. Chandra G, Banerjee A, Hati AK. Current filariasis situation in some pockets of Calcutta. Bull Sch Trop Med. 1994; 42:4-7.

6. Chandra G, Hati AK. Filariasis survey in a rural area of West Bengal. J Commun Dis. 1996; 28(3):206-208.

7. Chandra G. Studies on transmission dynamics of lymphatic filariasis in rural areas of West Bengal. Proc 
Zool Soc Cal. 1998; 51:116-128.

8. Rudra SK, Chandra G. Bancroftian filariasis in tribal population of Bankura district, West Bengal, India. Jap J Trop Med Hyg. 1998; 26:109-112.

9. Rudra SK, Chandra G. Comparative epidemiological studies on lymphatic filariasis, between tribal and nontribal populations of Bankura district, West Bengal, India. Ann Trop Med Parasit. 2000; 94:365-372.

10. Singh S, Bora D, Sharma RC, Datta KK. Bancroftian filariasis in Bagdogra town, district Darjeeling (West Bengal). J Commun Dis. 2002; 34:110-117.

11. Chandra G, Chatterjee SN, Das S, Sarkar N. Lymphatic filariasis in the coastal areas of Digha, West Bengal, India. Trop Doc. 2007; 37:136-139.

12. Paramanik M, Chandra G. Lymphatic filariasis in the foothill areas around Susunia of West Bengal in India. Asian Pac J Trop Med. 2009; 2:20-25.

13. Paramanik M, Chandra G. Studies on seasonal fluctuation of different indices related to filarial vector, Culex quinquefasciatus around foothills of Susunia of West Bengal, India. Asian Pac. J Trop Med. 2010; 3(9):727-730.

14. Medlock JM, Leach SA. Effect of climate change on vector-borne disease risk in the UK. The Lancet Infectious Diseases. 2015; 15:721-730.

15. Chandra G. Role of nature in limiting filarial transmission. J Basic and Applied Biomedicine. 1997; 5(4):21-23.

16. Chandra G. Nature limits filarial transmission. Parasit Vectors. 2008; 1: 13.

17. Harb M, Faris R, Gad AM, Hafez ON, Ramzy R, Buck AA. The resurgence of lymphatic filariasis in the Nile delta. Bull World Health Organ. 1993; 71:49-54.

18. Hunter JM. Elephantiasis: a disease of development in north east Ghana. Soc Sci Med. 1992; 35:627-645.

19. United Nations. Nations Human Settlements Programme. Washington, DC: United Nations, 2004.

20. Erlanger TE, Keiser J, De Castro MC, Bos R, Singer BH, Tanner $\mathrm{M}$ et al. Effect of water resource devlopment and management on lymphatic filariasis, and estimates of populations at risk. Am J Trop Med Hyg. 2005; 73(3):523533.

21. De SK, Chandra G. Studies on the filariasis vector Culex quinquefasciatus at Kanchrapara, West Bengal. Indian J Med Res. 1994; 99:255-258.

22. Polovodova VP. The determination of the physiological age of female Anopheles by the number of gonotrophic cycle completed. Medskaya parazit. 1949; 18:352-355.

23. Davidson G. Estimation of the survival rate of Anopheline mosquitoes in nature. Nature. 1954; 174:792-793.

24. Service MW. Mosquito ecology-Field sampling methods. Applied Science Publishers Ltd., London, 1976.

25. Gillies MT, Wilkes TJ. A study of the age-composition of populations of Anopheles gambiae Giles and A. funestus Giles in North Eastern Tanzania. Bull Entomol Res. 1965; 56:237-262.

26. Zar JH. Biostatistical analysis. ( $5^{\text {th }}$ edn), Pearson Prentice Hall, New Jersey, 2010.

27. Bryan JH, Oothman P, Andrews BJ, McGreevy PB. Effect of pharyngeal armature of mosquitoes on microfilariae of Brugia pahangi. Trans Roy Soc Trop Med Hyg. 1974; 68:14-19.

28. Wharton RH. The biology of Mansonia mosquitoes in relationto the transmission of filariasis in Malaya. Bull Inst Med Res. 1962; 11:114-122.
29. Jordan P, Goatly KD. Brancroftian filanasis in Tanganyika; aquantitative study on the uptake, fate and development of Wuchereria bancrofti. Ann Trop Med Parasit. 1962; 56:173-181.

30. Rozeboom LE, Bhattacharya NC, Gilotra SK. Observations on the transmission of filariasis in urban Calcutta. Am J Epidem. 1968; 87:616-632.

31. Haas R, Pal R. Mosquito larvivorous fishes. Bull. Entomol Soc Am. 1984; 30(1):17-25.

32. Bay EC. Other larvivorous fish. In: Chapman, H.C. (Ed.), Biological Control of Mosquitoes, Bulletin No. 6. American Mosquito Control Association, Fresno, CA, (Chapter 3), 1985, 18-24.

33. Lichtenberg ER, Getz W. Economics of rice-field mosquito control in California. Bioscience. 1985; 35(5):292-297.

34. Neng W, Shusen W, Guangxin H, Rongman X, Guangkun T, Chen Q. Control of Aedes aegypti larvae in household containers by Chinese cat fish. B World Health Organ. 1987; 65:503-506.

35. Morton RM, Beumer JP, Pollock BR. Fishes of a subtropical Australian saltmarsh and their predation upon mosquitoes. Environ Biol Fishes. 1988; 21:185-194.

36. Menon AGK. Indigenous Larvivorous Fishes of India. NIMR, New Delhi, India, 1991.

37. Torrente A, Rojas A, Durán A, Kano T, Orduz O. Fish species from mosquitos breeding ponds in northwestern Colombia: evaluation of feeding habits and distribution. Mem I Oswaldo Cruz. 1993; 88:625-627.

38. Tiwari SN. Evaluation of Colisa fasciatus for mosquito control in wells. In: Sharma, V.P., Ghosh, A. (Eds.), Larvivorous Fishes of Inland Ecosystem. NIMR, New Delhi, India, 1994, 127-134.

39. Chand SK, Yadav RS. Use of Oreochromis mossambicus (Peters) in controllingmosquito breeding in cow dung pits. In: Sharma, V.P., Ghosh, A. (Eds.), Larvivorous Fishes of Inland Ecosystems. Malaria Research Centre, Delhi, India, 1994, 115-120.

40. Homski D, Goren M, Gasith A. Comparative evaluation of the larvivorous fish Gambusia affinis and Aphanius dispar as mosquito control agents. Hydrobiologia. 1994; 284:137-146.

41. Kim HC, Kim MS, Yu HS. Biological control of vector mosquitoes by the use offish predators, Moroco oxycephalus and Misgurnus anguillicaudatus in the laboratoryand semi-field rice paddy. Korean Journal of Entomology. 1994; 24:269-284.

42. Chatterjee SN, Chandra G. Laboratory trials on the feeding pattern of Anopheles subpictus, Culex quinquefasciatus and Armigeres subalbatus by Xenentodon cancila fry. Environ Ecol. 1996; 14:173-174.

43. Chatterjee SN, Chandra G. Laboratory trials on the feeding pattern of Anopheles subpictus, Culex quinquefasciatus and Armigeres subalbatus larvae by Gambusia affinis. Sci Cult. 1997; 63:51-52.

44. Chatterjee SN, Das S, Chandra G. Gold fish (Carrasius auratus) as a strong larval predator of mosquito. Trans Zool Soc Ind. 1997; 1:112-114.

45. Lee DK. Predation efficacy of the fish muddy loach, Mysgurnus mizolepis, against, Aedes and Culex mosquitoes in laboratory and small rice plots. J AmMosquito Contr. 2000; 16:258-261.

46. Chatterjee SN, Ghosh A, Chandra G. Larvivorous 
potential of some cypriniformes fishes. Trans Zool Soc East Ind. 2001; 5:83-84.

47. Martinez-Ibarra JA, Guillen YG, Arredondo-Jimenez JI, Rodrigu-Lopez MH. Indigenous fish species for the control of Aedes aegypti in water storage tanks in Southern Mexico. BioControl. 2002; 47:481-486.

48. Walker K. A review of Control Methods for African Malaria Vectors EnvironmentalHealth Project (EHP). Activity Report, 2002, 108.

49. Ghosh A, Bhattacharjee I, Ganguly M, Mandal S, Chandra G. Efficacy of some common aquarium fishes as biocontrol agent of preadult mosquitoes. Bul Penelit Kesehat. 2004; 32:144-149.

50. Ghosh A, Bhattacharjee I, Chandra G. Biocontrol efficacy by Oreochromis niloticus niloticus. Journal of Applied Zoological Research. 2006; 17:114-116.

51. Hurst TP, Kay BH, Brown MD, Ryan PA. Laboratory evaluation of the effectof alternative prey and vegetation on predation of Culex annulirostris immatures by Australian native fish species. J Am Mosquito Contr. 2006; 22:412-417.

52. Marti GA, Azpelicueta MM, Tranchida MC, Pelizza SA, Garcia JJ. Predation efficiency of indigenous larvivorous fish species on Culex pipiens L. larvae (Diptera: Culicidae) in drainage ditches in Argentina. J Vector Ecol. 2006; 31:102-106.

53. Ghosh SK, Dash AP. Larvivorous fish against malaria vectors: a new outlook. Trans R Soc Trop Med Hyg. 2007; 101:1063-1064.

54. Van Dam AR, Walton WE. Comparison of mosquito control provided by the arroyochub (Gila orcutti) and the mosquito fish (Gambusia affinis). J Am Mosquito Contr. 2007; 23:430-441.

55. Bhattacharjee I, Aditya G, Chandra G. Laboratory and Field Assessment of the potential of larvivorous, airbreathing fishes as predators of culicine mosquitoes. Biological Control. 2009; 49:126-133.

56. Tranchida MC, Pelizza SA, Bisaro V, Beltrán C, García JJ, Micieli MV. Useof the neotropical fish Cnesterodon decemmaculatus for long-term control of Culex pipiens $\mathrm{L}$. in Argentina. Biological Control. 2010; 53:183-187.

57. Chandra G, Ghosh A, Bhattacharjee I, Ghosh SK. Use of larvivorous fish in biological and environmental control of disease vectors. Biological and environmental control of disease vectors. (eds. M.M. Cameron and L.M. Lorenz). 2013, 25-41.

58. Pramanik MK, Raut SK. Predation rhythm of the water bug Sphaerodema rusticum Fabricius. Environ Ecol. 2005; 23(3):707-713.

59. Aditya G, Ash A, Saha GK. Predatory activity of Rhantus sikkimensis and larvae of Toxorhynchites splendens on mosquito larvae in Darjeeling. J Vector Borne Dis. 2006; 43:66-72.

60. Aditya G, Saha GK. Predation of the beetle Rhantus sikkimensis (Coleoptera: Dytiscidae) on the larvae of Chironomus meigen (Diptera: Chironomidae) of the Darjeeling Himalayas of India. Limnologica. 2006; 36:251-257.

61. Saha N, Aditya G, Bal A, Saha GK. A comparative study of predation of three aquatic Heteropteran bugs on Culex quinquefasciatus larvae. Limnology. 2007a; 8:73-80.

62. Saha N, Aditya G, Bal A, Saha GK. Comparative studies on functional response of common heteropteran bugs of
East Calcutta Wetlands, Kolkata, India. International Review Hydrobiology. 2007b; 92:242-257.

63. Mandal SK, Ghosh A, Bhattacharjee I, Chandra G. Biocontrol efficiency of odonate nymphs against larvae of the mosquito, Culex quinquefasciatus Say, 1823. Acta Tropica. 2008; 106:109-114. 